\author{
А.О. Рожкевич, О.Г. Гоман, Л.І. Книш \\ Дніпровський наџіональний університет імені Олеся Гончара
}

\title{
ОЦІНКА ВПЛИВУ КІЛЬКОСТІ ЛОПАТЕЙ НА ЕНЕРГЕТИЧНІ ПОКАЗНИКИ ВІТРОАГРЕГАТУ 3 ВЕРТИКАЛЬНОЮ ВІССЮ ОБЕРТУ
}

В рамках класичної імпульсної теорії досліджено вплив числа лопатей вітротурбіни на загальні енергетичні показники вітроагрегату 3 вертикальною віссю обертання. Обраний інтегральний підхід зробив можливим використання дводискової імпульсної моделі для визначення основних питомих показників системи. Обчислення коефіціснта потужності виконано за знайденим значенням коефіціснта моменту на валу, який отримано числовим інтегруванням виразу для сумарного моменту, що створюється вітротурбіною. Для розрахунку тестової задачі використано класичний профіль NACA 0020. Значення аеродинамічних коефіцієнтів цього профілю знайдено шляхом обробки масиву експериментальних даних за дослідженнями його характеристик у повному діапазоні кутів атаки в аеродинамічних лабораторіях різних країн. Аналіз аеродинамічних коефіцієнтів проведено при фіксованому числі Рейнольдса для обраного профілю. На основі числового алгоритму розроблено програмний модуль, що дозволяс варіювати основні геометричні та динамічні параметри вітротурбіни. При розробці програмного продукту застосована однодискова модель, яка для означеної постановки задачі призвела до задовільних результатів. Проведене комп'ютерне моделювання виявило, що зменшення числа лопатей тягне за собою зміщення в бік зменшення числа швидкохідності максимального значення коефіціснта потужності. Визначено ефективний діапазон роботи модельного вітроагрегату, що відповідає обраному числу лопатей. Розроблений програмний модуль може бути використаний при проектуванні вертикально-осьових вітроустановок різної потужності та призначення.

Ключові слова: вертикально-осьова вітроустановка, дводискова імпульсна модель, лопать, коефіцієнт швидкохідності, вітровий потік, коефіцієнт моменту, коефіцієнт потужності, аеродинамічний профіль, трансцендентна система рівнянь.

В рамках классической импульсной теории исследовано влияние числа лопастей ветротурбины на общие энергетические показатели ветроагрегата с вертикальной осью вращения. Выбранный интегральный подход сделал возможным использование двухдисковой импульсной модели для определения основных удельных характеристик системы. Вычисление коэффициента мощности выполнено по найденному значению коэффициента момента на валу, который определен численным интегрированием выражения для суммарного момента, развиваемого ветротурбиной. Для расчета тестовой задачи использовался классический профиль NACA 0020. Значения аэродинамических коэффициентов этого профиля определялись путем обработки массива экспериментальных данных, полученных при исследованиях его характеристик в полном диапазоне углов атаки в аэродинамических лабораториях разных стран. Анализ аэродинамических коэффициентов проводился при фиксированном числе Рейнольдса для выбранного профиля. На основе численного алгоритма разработан программный модуль, позволяющий варьировать основные геометрические и динамические параметры ветротурбины. При разработке программного продукта использовалась однодисковая модель, которая при данной постановке задачи привела к удовлетворительным результатам. Проведенное компьютерное моделирование показало, что уменьшение числа лопастей влечет за собой смещение в сторону уменьшения числа быстроходности максимального значения коэффициента мощности. Определен эффективный диапазон работы модельного ветроагрегата, соответствующий выбранному числу лопастей. Разработанный 
программный модуль может быть использован при проектировании вертикально-осевых ветроустановок различной мощности и назначения.

Ключевые слова: вертикально-осевая ветроустановка, двухдисковая импульсная модель, лопасть, коэффициент быстроходности, ветровой поток, коэффициент момента, коэффициент мощности, аэродинамический профиль, трансцендентная система уравнений.

Within the framework of the classical impulse theory, the influence of the number of wind turbine blades on the general energy parameters of a wind turbine with the vertical-axis of rotation was investigated. The integral approach allowed using a two-disk impulse model to determine the main specific characteristics of the system. The power factor was calculated on the basis of the found value of the torque coefficient on the shaft, which, in turn, was determined by numerical integration of the expression for the total torque developed by the wind turbine. The NACA 0020 classic profile was used to calculate the test problem. The aerodynamic coefficients of this profile were determined by processing an array of experimental data obtained by studying its characteristics within a full range of attack angles in aerodynamic laboratories of different countries. The analysis of the aerodynamic coefficients was carried out at a fixed Reynolds number for the chosen profile. Based on the numerical algorithm, a software module has been developed that allows to vary the basic geometric and dynamic parameters of the wind turbine. When developing the software product, a single-disk model was used, wich this formulation of the problem, gives satisfactory results. Carried out computer simulation showed that when the number of blades is reducies, the maximum value of the power factor shifts in the direction of reducing the number of speed. The effective range of operation of the model wind turbine corresponding to the selected number of blades is determined. The developed software module can be used in the design of vertical-axis wind turbines of different power and purpose.

Key words: vertical-axial wind turbine, double-disk impulse theory, blade, speed ratio, wind flow, torque coefficient, power factor, aerodynamic profile, transcendental system of equations.

Вступ. Вітроенергетика в останній час стає однією 3 найбільш важливих галузей промисловості. Про це свідчить той факт, що щорічний приріст потужностей нових вітроенергетичних установок в світі складає приблизно $20 \%$. Провідні позиції у цьому процесі займають такі країни як Німеччина, Іспанія, США, Індія, Китай, Данія, Великобританія, Нідерланди, Канада, Японія та інші [1].

Для України широке впровадження вітроенергетичних систем може стати одним 3 елементів енергетичної незалежності та поступового економічного відродження. Запорукою цього є позитивний досвід багатьох розвинених країн. Однак пряме запозичення цього досвіду та використання вітродвигунів, виготовлених за кордоном, може виявитись малоефективним. Це пов'язано 3 тим, що проектування вітроагрегатів неможливо без тісної «прив'язки» до вітрових умов регіону розташування.

Дані, що характеризують вітровий потенціал України, свідчать про те, що на переважній частині території країни середньорічна швидкість вітру не перевищує 4 м/с, а більшість промислово виготовлених вітродвигунів країн Європи, США і Канади розраховані на роботу з номінальною швидкістю вітру $15-20$ м/с. Такі системи не можуть ефективно використовуватися в Україні. Тому постає питання пошуку також ефективних проектних рішень вітроагрегатів, що мають задовільні енергетичні показники в умовах низької швидкості вітру [2].

3 цього приводу перспективними вважаються вітроенергетичні установки 3 вертикальною віссю обертання (рис.1). Не менш важливе також те, що такі пристрої зручно використовувати в автономних системах енергозабезпечення, що також $\epsilon$ актуальним у теперішній час. 


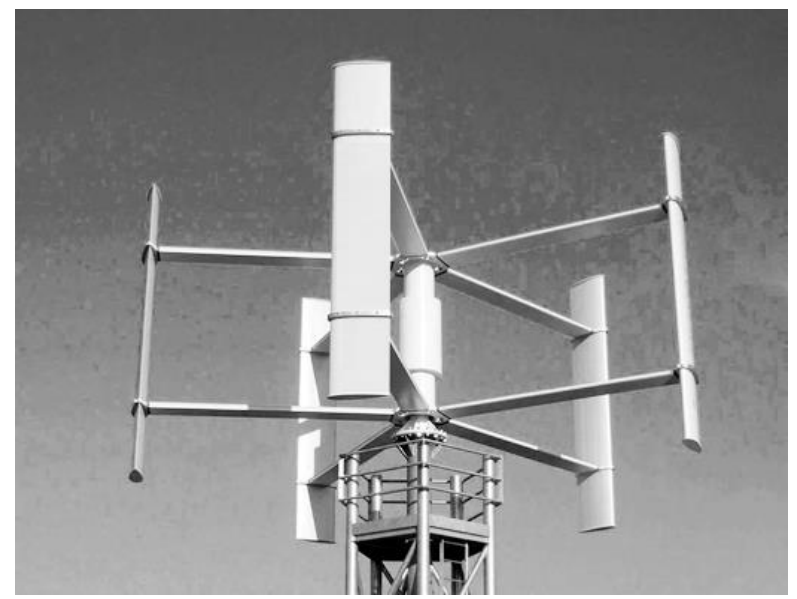

Рис. 1. Вітроенергетична установка з вертикальною віссю оберту

Вибір методу дослідження. Вітроенергетична установка є складним об'єктом дослідження. Тривимірний характер вітрового потоку, що набігає на лопаті та його нестаціонарність робить чисельне дослідження таких систем досить коштовним [3]. Для його проведення необхідно мати дані експериментальних досліджень аеродинамічних характеристик профілів лопатей, які передбачаються для використання. Такі роботи проводяться лише в спеціалізованих аеродинамічних центрах $\mathrm{i}$, як правило, $€$ їх власністю. Але навіть маючи значення аеродинамічних коефіцієнтів, розв’язати систему рівнянь Нав'є-Стокса для вибраного профілю досить складно. Тому на сьогоді такі методи не широко поширені при проектуванні.

Більш популярними та доступними можна вважати інженерні методи, насамперед ті, що базуються на класичних підходах, адаптованих для розрахунку вертикально-осьових вітродвигунів. Один $з$ таким підходів представлено в даній роботі.

Загальна характеристика математичної моделі. В основу математичної моделі покладено дводискову імпульсну теорію, суть якої зводиться до того, що і в навітряній, і у підвітряній частині вітротурбіни положення «активних дисків» залишається невизначеним, але на цих дисках мають виконуватися закони збереження в інтегральному сенсі.

В математичному плані реалізація дводискової імпульсної теорії зводиться до наступного алгоритму: сили, що діють на лопаті і траверси, 3 одного боку, виражаються через аеродинамічні коефіцієнти профілів лопаті i траверс (розрахованих за місцевими кутами атаки та місцевими відносними швидкостями, які заздалегідь невідомі); з іншого - ті ж самі сили виражаються за допомогою теореми імпульсів. Математично такий баланс сил формалізується у вигляді системи двох трансцендентних рівнянь, розв'язок яких передбачає знаходження основних енергетичних характеристик вітроагрегату - коефіцієнтів потужності та моменту. 
На рис. 2 схематично показано розподіл вітрових потоків для дводискової розрахункової моделі.

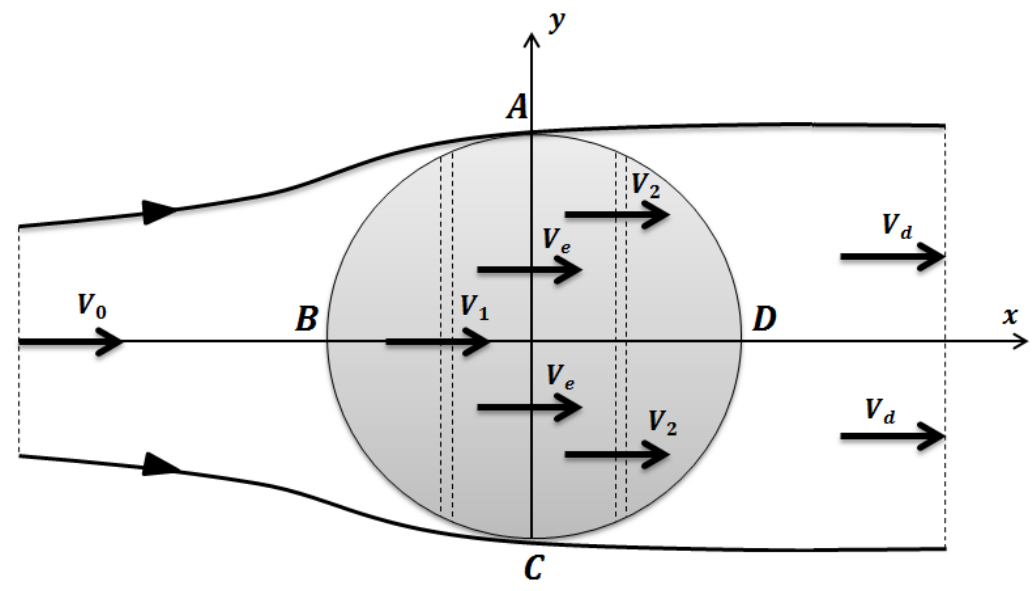

Рис. 2. Схема дводискової моделі

Перпендикулярно умовному перетину вітротурбіни набігає вітровий потік $\vec{V}_{0}$. У навітряній частині він має середню швидкість $\vec{V}_{1}$, у підвітряній $-\vec{V}_{2}$. Швидкість потоку в діаметральній площині дорівнює $\vec{V}_{\mathrm{e}}$. Граничне асимптотичне значення швидкості, що знаходиться за підвітряною частиною вітротурбіни $-\vec{V}_{d}$.

Що стосується всіх цих умовно введених швидкостей, то в імпульсній теорії вони вважаються сталими величинами, котрі не залежать ні від просторових координат, ні від часу (при фіксованих величинах швидкості вітру та кутової швидкості обертання). Тому $V_{1}$ та $V_{2}$ можна вважати середніми значеннями швидкостей у навітряній і підвітряній частині, відповідно.

Застосовуючи закон про зміну кількості руху для елементарного струменю та враховуючи задекларований розподіл швидкостей, отримуємо вирази для сумарних сил у вигляді [4]:

$$
\begin{gathered}
X_{1 \Sigma}=4 R k \rho d z V_{1}^{2}\left(\frac{V_{0}}{V_{1}}-1\right) \\
X_{2 \Sigma}=4 R k \rho d z V_{2}^{2}\left(2 \frac{V_{1}}{V_{2}}-\frac{V_{0}}{V_{2}}-1\right),
\end{gathered}
$$

де $R$ - радіус вітроустановки; $k$ - коефіцієнт затінення для проходження об'єму вітрового потоку лопатями; $\rho$ - густина вітрового потоку.

Слід зазначити, що у подальшому всі рівняння будуть застосовуватись до деякого шару висотою $d z$, що знаходиться між перерізами $z$ та $z+d z$.

3 іншого боку, осередненні значення поздовжніх сил за напівоберт вітроколеса для навітряної та підвітряної частин, відповідно, можна виразити за допомогою аеродинамічних коефіцієнтів. 
Для однієї лопаті в шарі $d z$ середні значення повздовжних сил дорівнюють

$$
\bar{X}_{1}=\frac{1}{\pi} \int_{\frac{\pi}{2}}^{\frac{3 \pi}{2}} d X_{1} d \beta, \bar{X}_{2}=\frac{1}{\pi} \int_{-\frac{\pi}{2}}^{\frac{\pi}{2}} d X_{2} d \beta,
$$

де $d X_{1,2}-$ складові елементарних сил вздовж вісі $O x$, а $\beta$ - азимутальний кут (рис. 3).

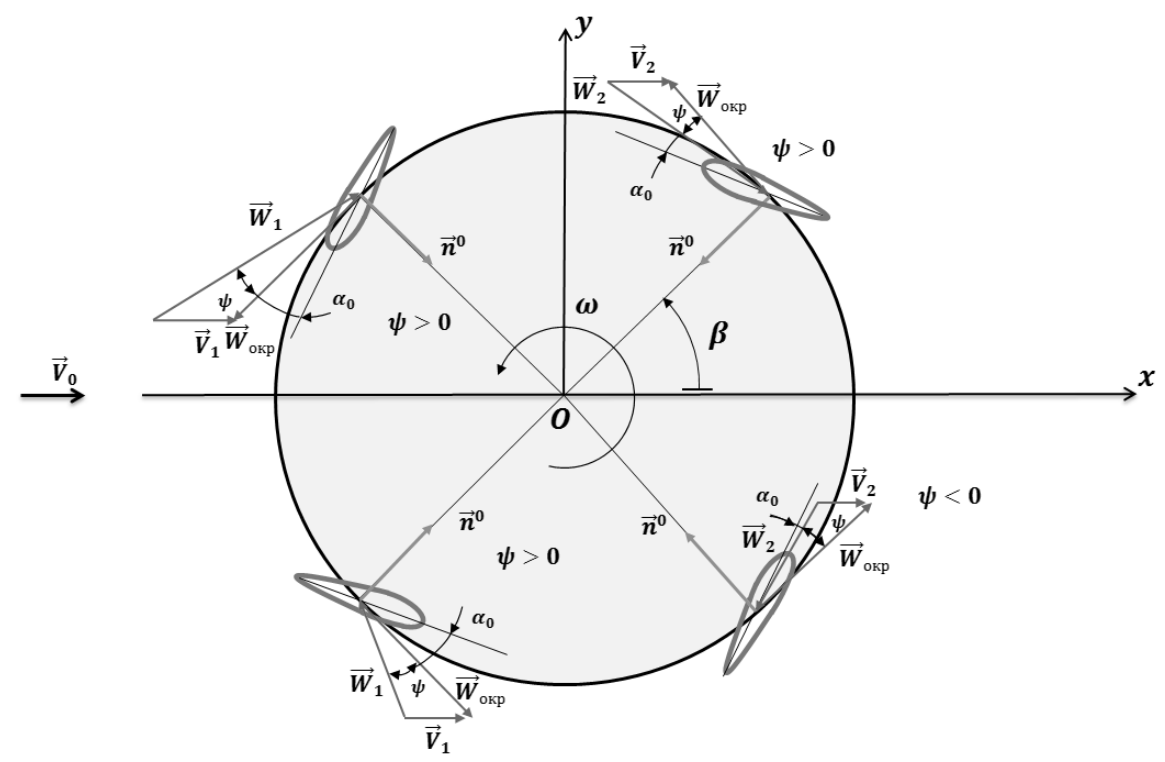

Рис. 3. Схема відносних швидкостей та кутів атаки елементів лопаті в залежності від положення азимутального кута

Складові елементарних сил $d X_{1,2}$ залежать від відносної швидкості $\vec{W}_{1,2}$ та мають вигляд

$$
d X_{1,2}=\frac{1}{2} \rho W_{1,2}^{2} c d z\left(c_{x} \sin (\beta-\psi)-c_{y} \cos (\beta-\psi)\right),
$$

де $c$ - довжина хорди лопаті; $c_{x}(\alpha)$ і $c_{y}(\alpha)$ - аеродинамічні коефіцієнти обраного профілю лопаті; $\alpha=\alpha_{0}+\psi-$ місцевий кут атаки; $\psi-$ кут між вектором відносної швидкості $\vec{W}$ і напрямком $\vec{W}_{\text {окр }}-$ лінійної швидкості лопаті по колу; $\alpha_{0}-$ кут установки лопаті відносно дотичної до кола (вважається додатнім, якщо передня кромка профілю відхиляється всередину вказаного кола, i від'ємним, якщо - назовні).

Значення відносної швидкості в залежності від азимутального кута $\beta$ має вигляд:

$$
\vec{W}_{1,2}=\vec{V}_{1,2}-\vec{W}_{\text {окр }}=\left(V_{1,2}+R \omega \sin \beta\right) \vec{x}^{0}-R \omega \cos \beta \vec{y}^{0} .
$$

У формулах (3) - (5) індекси «1» та «2» та межі інтегрування відносяться до навітряної та підвітряної частин вітроколеса відповідно. Схематично розподіл 20 
відносних швидкостей та кутів атаки елементів лопаті в залежності від азимутального кута зображено на рис. 3.

Якщо число лопатей дорівнює $N$, то за один оберт половина цього числа знаходиться на навітряній стороні, а інша половина - на підвітряній; так що, інтегруючи вираз (4) з урахуванням кількості лопатей, будемо мати

$$
X_{1,2}=\frac{N}{4 \pi} \rho c d z \int_{\frac{\pi}{2}\left(-\frac{\pi}{2}\right)}^{\frac{3 \pi}{2}\left(\frac{\pi}{2}\right)} W_{1,2}^{2}\left(c_{x}(\alpha) \sin (\beta-\psi)-c_{y}(\alpha) \cos (\beta-\psi)\right) d \beta .
$$

Прирівнюючи вирази для сил, отриманих за допомогою закону імпульсу (1) та (2), та через аеродинамічні коефіцієнти (6), отримуємо наступну систему рівнянь для знаходження величин невідомих швидкостей $V_{1}$ та $V_{2}$ :

- для навітряної частини:

$$
\frac{V_{0}}{V_{1}}-1=F_{1},
$$

- для підвітряної частини:

$$
2 \frac{V_{1}}{V_{2}}-\frac{V_{0}}{V_{2}}-1=F_{2} .
$$

У рівняннях $(7)-(8)$ безрозмірні величини $F_{1,2}$ мають вигляд:

$$
F_{1,2}=\mu_{1} \int_{\frac{\pi}{2}\left(-\frac{\pi}{2}\right)}^{\frac{3 \pi}{2}\left(\frac{\pi}{2}\right)} \bar{W}_{1,2}^{2}\left(c_{x} \sin (\beta-\psi)-c_{y} \cos (\beta-\psi)\right) d \beta,
$$

де $\mu_{1}=\frac{N c}{16 \pi R k}-$ коефіцієнт, що враховує геометричні параметри вітротурбіни; $\bar{W}_{1,2}=\frac{W_{1,2}}{V_{1,2}}-$ безрозмірна відносна швидкість.

Знаходження коефіцієнта моменту та коефіцієнта потужності. Основними енергетичними характеристиками будь-якого вітроагрегату $\epsilon$ коефіцієнт потужності

$$
C_{p}=\frac{2 P}{\rho V_{0}^{3} F},
$$

та коефіцієнт обертального моменту на валу

$$
C_{m}=\frac{2 M}{\rho V_{0}^{2} F R},
$$

де $P$ - величина потужності, що відбирається від вітрового потоку вітроколесом; $F$ - площа живого перерізу; $M$ - момент, зумовлений обертовою силою.

Знаходження цих параметрів на основі математичної моделі (7) - (9) базується на наступному алгоритмі: момент $M$ виражається сумою середніх значень сумарних моментів $M_{z 1}$ та $M_{z 2}$, знайдених за допомогою аеродинамічних 
коефіцієнтів від усіх лопатей у навітряній та у підвітряній частинах вітротурбіни, відповідно, тобто

$$
C_{m}=\frac{2\left(M_{z 1}+M_{z 2}\right)}{\rho V_{0}^{2} F R},
$$

де

$$
M_{z 1,2}=\frac{N}{4 \pi} \rho c \int_{\frac{\pi}{2}\left(-\frac{\pi}{2}\right)}^{\frac{3 \pi}{2}\left(\frac{\pi}{2}\right)}\left(V_{1,2}^{2}+2 V_{1,2} R \omega \sin \beta+R^{2} \omega^{2}\right)\left\{R\left(c_{y} \sin \psi-c_{x} \cos \psi\right)\right\} d \beta .
$$

Розрахувавши інтеграли (13) за допомогою класичних квадратурних формул можна знайти величину обертального моменту на валу $C_{m}[5]$.

При обертанні вітроколеса 3 фіксованою сталою кутовою швидкістю $\omega$ середня потужність $P_{c p}$, що розвивається за один оберт, і середній момент $M_{c p}$, зумовлений обертовою силою, пов'язані рівністю

$$
P_{c p}=M_{c p} \omega
$$

тобто

$$
C_{p}=C_{m} Z_{0}
$$

де $Z_{0}=\frac{\omega R}{V_{0}}-$ коефіцієнт швидкохідності.

Таким чином, на основі математичної моделі (7) - (9) можуть бути розраховані середні швидкості $V_{1}$ та $V_{2}$ в залежності від швидкості вітрового потоку $V_{0}$ та числа $Z_{0}$. Це дозволяє знайти обертальні моменти $M_{z 1}$ та $M_{z 2}$, значення яких потрібні для знаходження коефіцієнтів потужності та обертального моменту на валу.

Результати чисельного моделювання. Для визначення основних енергетичних показників вітроагрегату на основі запропонованої математичної моделі було побудовано ітераційний чисельний алгоритм. При проведенні тестових розрахунків, що представлені у цій статті, була реалізована спрощена однодискова імпульсна модель, в якій швидкість потоку навітряної частини вітроколеса відповідала за середнє значення швидкості потоку у всьому вітроколесі.

Для визначення зв'язку між коефіцієнтами швидкохідності $Z_{0}$ та $Z_{1}=\frac{\omega R}{V_{1}}$ рівняння (7) має вигляд:

$$
\frac{Z_{0}}{Z_{1}}-1=F_{1},
$$

де вираз (9), на цей раз, виглядає так

$$
F_{1}=\mu_{1} \int_{0}^{2 \pi} \bar{W}_{1}^{2}\left(c_{x} \sin (\beta-\psi)-c_{y} \cos (\beta-\psi)\right) d \beta .
$$


Момент $M_{z 1}$ відповідає за сумарний момент у всьому вітроколесі вітротурбіни, і вираз (12) приймає вигляд:

$$
C_{m}=\frac{N}{4 \pi} \frac{c}{R F} \frac{Z_{0}^{2}}{Z_{1}^{2}} \int_{0}^{2 \pi}\left(1+2 Z_{1} \sin \beta+Z_{1}^{2}\right)\left\{R\left(c_{y} \sin \psi-c_{x} \cos \psi\right)\right\} d \beta
$$

Розрахунок енергетичних характеристик вітроустановки проводився для профілю NACA 0020 [6]. На рис. 4 наведено залежності коефіцієнта крутного моменту $C_{m}$ та коефіцієнта потужності $C_{p}$ вітрогенератора від числа швидкохідності $Z_{0}$.

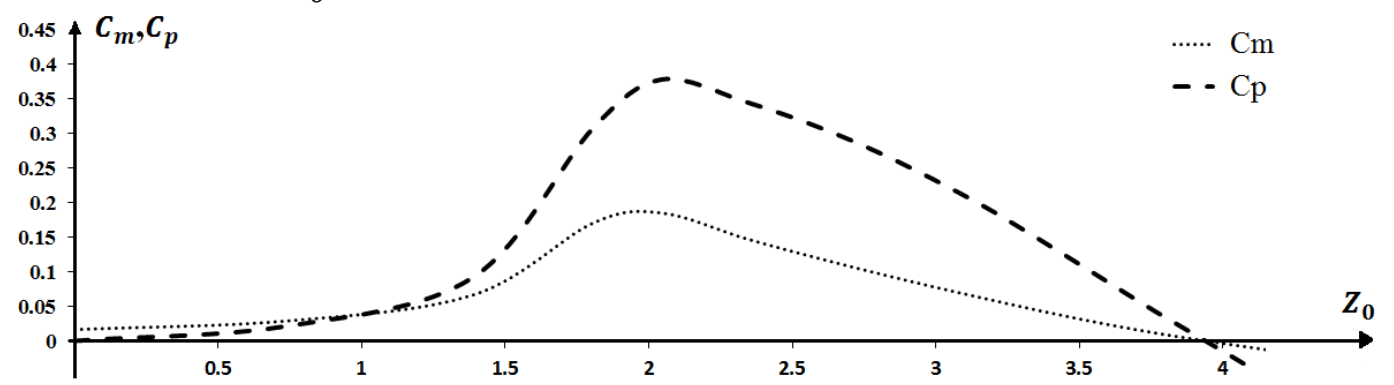

Рис. 4. Графік залежності коефіцієнтів моменту $C_{m}$ та потужності $C_{p}$ вітроустановки від числа швидкохідності $Z_{0}$

Із рис. 4 видно, що для розглянутого вітроагрегату робочий діапазон за числом швидкохідності складає $0<Z_{0} \leq 3.95$, при $Z_{0} \geq 3.95$ потужність від’ємна, що свідчить про те, що робота установки стає неефективною - для забезпечення такого режиму роботи установка повинна споживати енергію зовні.

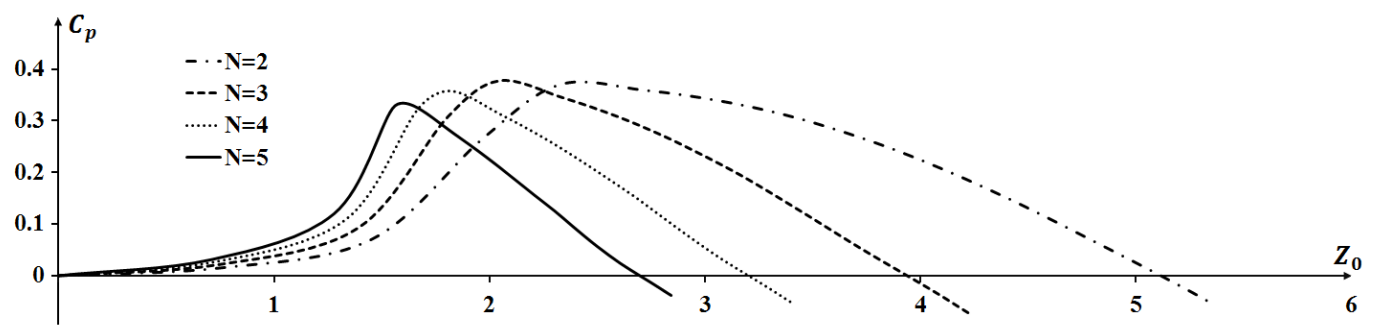

Рис. 5. Графік залежності коефіцієнту потужності $C_{p}$ від числа швидкохідності для різної

$$
\text { кількості лопатей }
$$

На рис. 5 показано залежність коефіцієнту потужності від кількості лопатей для вибраного модельного вітроагрегату. Як видно, при зменшенні кількості лопатей максимум значення коефіцієнта потужності зміщується в сторону зменшення числа швидкохідності. Зі збільшенням кількості лопатей модельного вітроагрегату ефективний діапазон його роботи зменшується.

Висновки. У роботі представлено математичну модель розрахунку енергетичних показників вітроагрегату з вертикальною віссю оберту, що базується на дводисковій імпульсній теорії. Створено чисельний алгоритм та проведено 
параметричні дослідження енергетичних характеристик модельного вітроагрегату, виявлено вплив на них кількості лопатей та їх геометричої досконалості. Теоретичні та практичні дослідження, що були виконані у роботі, дозволяють використовувати отримані дані у подальших розрахунках вітроагрегатів указаного типу, проводити порівняння різних методів розрахунку, вдосконалювати їх, тощо.

\title{
Бібліографічні посилання
}

1. Абрамовський,С.P. Проблеми оптимізації параметрів вітряних двигунів [Текст] / Є.Р. Абрамовський. - Д.: Наука і освіта, 2014. - 273 с.

2. Карплюк, В.I. Посібник до вивчення дисципліни «Аеродинаміка вітроенергетичних установок» [Текст] / В.І. Карплюк, М.М.Личагін. - Д.: РВВ ДНУ, 2008. - 56 с.

3. Тарасов, С.В. Вычислительная гидродинамика на службе ветроэнергетики [Текст] / С.В. Тарасов, Д.А. Редчиц, О.Б. Полевой [та ін.] // Вісн. ДНУ. Сер.: Механіка. - 2016. - №5, Т. 24 (Вип.20) - С. $38-47$.

4. Рожкевич, А.О. Использование двухдисковой импульсной теории для расчёта вертикально-осевого ветрогенератора [Текст] / А.О. Рожкевич, Л.И. Кныш // Материалы XIX Международной молодёжной конференции «Людина і космос». - Дніпро, 2017. - С.123.

5. Турчак, Л.И. Основы численных методов: Учеб. пособие. [Текст] / Л.И. Турчак М.: Наука. Гл. ред. физ.-мат. лит., 1987. - 320 с.

6. Aerodynamic Characteristics of Seven Symmetrical Airfoil Sections Through 180-Degree Angle of Attack for Use in Aerodynamic Analysis of Vertical Axis Wind Turbines [Text] / Sheldahl [et al.] - Sandia National laboratories. Energy report, 1981. - 120 p.

Надійшла до редколегії 20.04.2018

УДК 539.3

\author{
M.S. Arsenyuk
}

Institute of transport systems and technologies of the National academy sciences of Ukraine

\section{NUMERICAL SIMULATION OF UNSTEADY THREE- DIMENSIONAL DETACHED FLOW AROUND THE REFERENCE AHMED CAR MODEL}

Для численного моделирования обтекания воздухом упрощенной модели автомобиля типа Ahmed Car применены осредненные по Рейнольдсу уравнения Навье-Стокса вязкой несжимаемой жидкости. При замыкании системы уравнений использовалась модель турбулентности SST (Shear Stress Transport). Численное решение исходной системы уравнений получено методом контрольных объемов. Численная методика реализована в программнометодическом обеспечении, написанном на языке Fortran. Расчетная область вокруг корпуса Ahmed Car разделена на контрольные объемы неструктурированной гексаэдрической сеткой, состоящей из 3.5 миллионов ячеек. Проведены расчеты двух вариантов эталонной геометрии -с углом заднего скоса $25^{\circ}$ и 35․ Число Рейнольдса, рассчитанное по длине корпуса, равнялось 2.6 млн. Выполнена визуализация результатов расчетов, их анализ и сравнение с работами других авторов. Представлены распределения модуля скорости, давления и линии тока в плоскости симметрии Ahmed Car, распределения векторов скорости в поперечном сечении за корпусом Ahmed Car, a также распределение коэффициента давления и коэффициента трения по 